\title{
The Reason Analysis of the Resistance Degradation of Steel Gates Components
}

\author{
Jiangchuan Liu, Zhenghui Liu, Wei Ji \\ School of Water Resources and Environmental Engineering, \\ Changchun Institute of Technology, \\ Changchun, China
}

\begin{abstract}
The hydraulic steel gate, due to its specific operating environment, the corrosion is a major factor that causes its degradation. In this paper, by the sem and Tensile testing machine, according to the experimental study on the material of existing hydraulic steel gate structure, its chemical composition and mechanical index can be tested, and the reasons of hydraulic steel gate components resistance degradation can also be obtained. The results show that: the chemical composition and mechanical index of the hydraulic steel gate do not change; the main reason of the structural resistance degradation is that the corrosion causes decrease of structural stress area, when the structural resistance is less than the load effect, the structure is in failed state, and structural reliability will be reduced.
\end{abstract}

Keywords-hydraulic steel gate; chemical composition; mechanics index

\section{INTRODUCTION}

The hydraulic steel gate is the same as other steel structure; its resistance will decay with the extension of working hours. Due to the special operating environment, the corrosion is the main reason that causes the hydraulic steel gate resistance attenuation. The corrosion is not only limited to the decrease of the effective area, but also can produce partial rust pits, cause local stress concentration, reduce the bearing capacity of structure, impel structural brittle fracture, lead to unexpected engineering accident, Thereby, the reliability of the structure will decrease [1-4]. At present, while the specific experimental studies are rare, in this paper, the reasons of hydraulic steel gate resistance degradation are further analyzed which is based on the materials experimental analysis of the specific steel gate project.

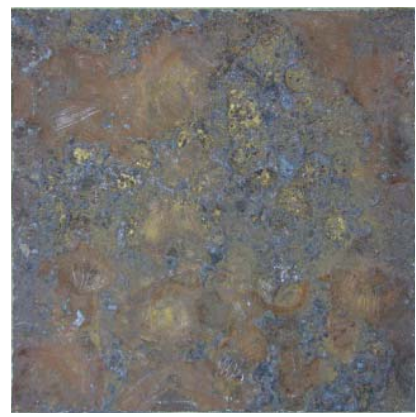

Figure 1. Experimental steel.

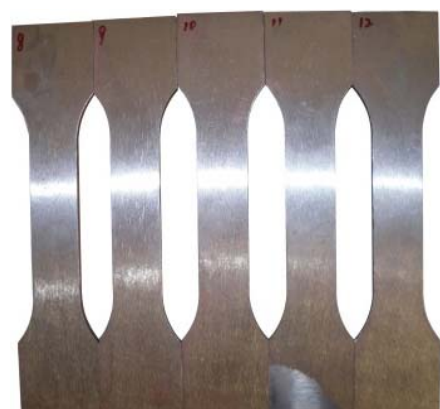

Figure 2. Tensile sample.

\section{EXPERIMENTAL MATERIALS AND METHODS}

The object of this experiment is an actual engineering gate panel which was put into operation from 1980 to 2011. The surface corrosion of the steel gate panel is serious (Figure 1), through the sem observation on the surface of steel gate panel and the chemical analysis of the surface composition of the corrosion products; at the same time, according to GBT228-2002 "standard of tensile experiment," the panel is processed into standard tensile specimens (Figure 2) the panel of the mechanics index are tested though mechanical testing machine.

The steel gate was built in the 1980s, at that time, the material of the steel gate is A3 steel which is an old standard steel grade, there is no such designation in the current specification. In the specification (GB221-79), the A3 steel is included in the Q235 that is equivalent of Q235A steel. Therefore, in this paper, the chemical composition and physical properties of the Q235A steel were analyzed with the experiment according to the specification (GB/T700-1988) of carbon structural steel; the results have certain credibility.

\section{EXPERIMENT RESULTS AND ANALYSIS}

In hostile environments, the hydraulic steel structures resistance is attenuated with the extension of working hours, the main reason is the corrosion. Ren Yushan think the corrosion of gate member lead to section size decreases, and stress increase, he put forward the concept of average corrosion loss, and uses the average corrosion quantity instead of the cross section thickness reduction, by this way, the residual life of gate components are analyzed [5]. Zhou Jianfang Li Dianqing and others analyze the time-dependent reliability of valve components and structure, using the average corrosion quantity 
calculating the time reliability index as well [6]. Yuan Zexi and others obtain multi-groups of corrosion of steel by five kinds of accelerated corrosion method (acid soil, salt, salt, acid atmosphere and wet and heat cycle), the influence of corrosion degree on the mechanical properties such as Steel yield strength, ultimate strength, elongation are analyzed by the mechanical property test of the Corrosion specimens, the results showed that the elongation decline in the power relations, yield strength and ultimate strength linearly decrease [7]. Domestic scholars generally agree that the steel structure resistance deterioration is mainly the corrosion, as it makes the structure of the stress area decrease. For the steel itself, as long time run, the change of the chemical composition and mechanical index is no specific test analysis, therefore, in this article, through the sample analysis of hydraulic steel gate which is operating on more than 30 years, it shows that the changes in the chemical com-position and the mechanics index of the steel structure material after a long time run.

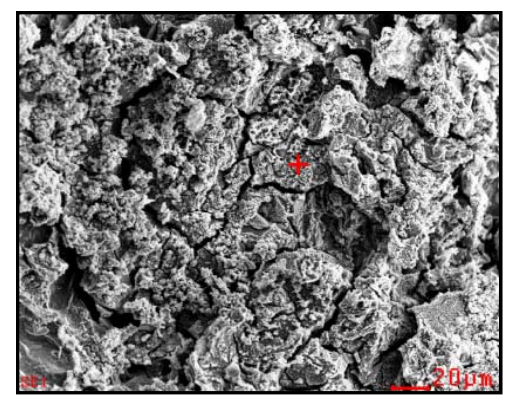

Figure 3. Surface of corrosion.

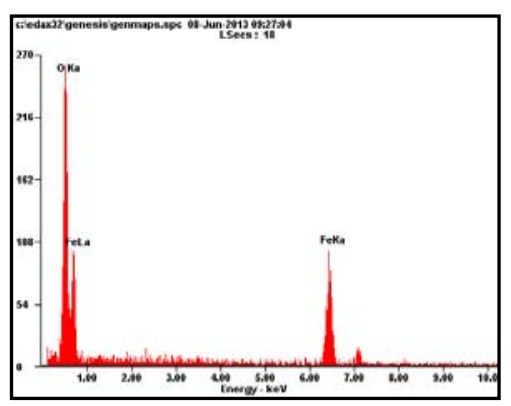

Figure 4. Energy spectrum.

\section{A. Corrosion Surface Observation}

The appearance morphology of rusted panel under the sem is shown in Figure 3. As can be seen, its surface is full of rust, the Corrosion products into blocks, through the analysis of the energy spectrum, the number of oxygen percentage is $61.33 \%$, the number of iron atoms percentage is $38.67 \%$, the ratio is close to $3: 2$, it can be judged, after years of corrosion, The final corrosion product of the steel gate is $\mathrm{Fe} 2 \mathrm{O} 3$. The corroded surface can be seen from Figure 3, the $\mathrm{Fe} 2 \mathrm{O} 3$ piles up together, and there are some cracks on the surface. So the bear (pressure) pulling force is small, therefore, with the increase of corrosion, the rust layer of the hydraulic steel gate member will also increase. The thickness of the steel matrix gradually decreases, under the condition of the same tension, which inevitably leads to increased stress. The total led to the decrease of the gate structure resistance.

\section{B. Chemical Compositions}

To show the change of its chemical composition, the experimental results should be compared with the specification and the steel production level of the day because of the experiment obtained in 1980s. Yuan Zexi and others analyzed Anshan iron and Wuhan iron production, and obtained the statistics of the steel in the various chemical elements, this represented the technology level of domestic steel production at that time. In this paper, to measure the chemical composition of the steel, the chemical composition of two points on the experimental steel is analyzed; at the same time, by calculating the average of two test result, the percentage of chemical elements is obtained, according to this, the chemical composition change of the steel which is operating on a long time is analyzed. The results are shown in Table I.

TABLE I. CHEMICAL COMPOSITION CONTRAST OF THE EXPERIMENTAL STEEL

\begin{tabular}{|c|c|c|c|c|}
\hline $\begin{array}{c}\text { Chemical } \\
\text { Composition } \\
\text { w\% }\end{array}$ & Wisco & Anshan & $\begin{array}{c}\text { GB/T700- } \\
1988\end{array}$ & $\begin{array}{c}\text { Experimental } \\
\text { Steel }\end{array}$ \\
\hline $\mathrm{C}$ & 0.1627 & 0.1986 & $0.14-0.22$ & 0.11904 \\
\hline $\mathrm{Si}$ & 0.2322 & 0.2392 & $\leq 0.3$ & 0.00719 \\
\hline $\mathrm{Mn}$ & 0.5361 & 0.4857 & $0.3-0.65$ & 0.408815 \\
\hline $\mathrm{S}$ & 0.0233 & 0.0344 & $\leq 0.05$ & 0.012085 \\
\hline $\mathrm{P}$ & 0.00199 & 0.0121 & $\leq 0.045$ & 0.008505 \\
\hline $\mathrm{Cr}$ & 0.0132 & 0.0129 & - & 0.00458 \\
\hline $\mathrm{Mo}$ & 0.001 & 0.003 & - & 0.00105 \\
\hline $\mathrm{Ni}$ & 0.0098 & 0.0101 & - & 0.00422 \\
\hline $\mathrm{Ti}$ & 0.00198 & 0.00154 & - & 0.00056 \\
\hline
\end{tabular}

Through the above analysis, the chemical compositions of steel sample still meet the requirements of the chemical composition of carbon structural steel based on the standard of GB/T700-1988, at the same time, the chemical elements content in the steel which are produced in Wisco and Anshan are compared and analyzed. In addition to the $\mathrm{C}$ within $2.18 \%$ (Wisco), 3.98\% (Anshan), Si within $11.25 \%$ (Wisco), $11.60 \%$ (Anshan), Mn is $6.36 \%$ (Wisco), 3.84\% (Anshan), the remaining elements are less than $1 \%$. The reason for this phenomenon is that the steel used in the different regions is different, that lead to some deviations of the chemical elements of steel. As the result shown, with the long time running, the chemical compositions of steel are almost no changing.

\section{Mechanical Properties}

According to specifications (GBT228-2002) "standard of tensile experiment" [8], the Corroded steel plate is processed into twelve standard tensile specimens; then makes these specimens divided into three groups for tensile experiment. The result is shown in Figure 4. 
Through the experiment, the minimum tensile strength in each set of tensile specimen is $377.5 \mathrm{MPa}, 378.15 \mathrm{MPa}$, 417.1 MPa, 378.15 MPa, the minimum yield strength 242 $\mathrm{MPa}$, respectively, 249.625 MPa, 280.5 MPa, 280.75 MPa, the elongation of the lowest value is $32 \%, 24 \%, 32 \%$, and $24 \%$, respectively. In addition to the elongation of the group 2 no. 2 tensile specimen does not meet the specification (GB/T700-1988) "carbon structural steel" requirement, the rest of the specimens all meet specification requirements [9]. The average of each set of tensile specimens of the mechanics index is compared with the standard of the mechanics index; the results are shown in Table II.

TABLE II. THE COMPARISON OF THE EXPERIMENTAL STEEL MECHANICAL PERFORMANCE

\begin{tabular}{|c|c|c|}
\hline Mechanics Index & GB/T700-1988 & Mechanics Index \\
\hline Yield strength (MPa) & 235 & 274.594 \\
\hline Tensile strength (MPa) & $372-461$ & 409.014 \\
\hline The elongation (\%) & 26 & 31.2 \\
\hline \\
\hline
\end{tabular}

Figure 5. The sample of stretching before.

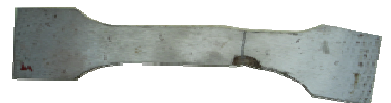

Figure 6. The sample of after drawing.

Through comparative analysis, after years of corrosion, the mechanical parameters of the steel are basically no change. Yuan Zexi and others concluded that the Yield strength and ultimate strength linearly decrease Elongation decrease under the power relationship [7].

The author believes that the change is not the steel yield strength and ultimate strength, but with the increase of corrosion, the stress area is gradually decreasing, while others obtained the results in the case of a certain area, the calculated values of yield strength and ultimate strength will decrease inevitably. Therefore, in this paper, the yield strength, the elongation and ultimate strength of the corrosion steel do not change. The stress area of the components is a linear downward trend with the increase of time. Yuan Zexi and others' conclusion mainly due to the local rust pit of stress concentration. In this paper, the second group of no. 2 of the experimental specimens (Figures 5 and 6 ) is in the process of machining with rust corrosion pits, and it finally leads to stress concentration and elongation decrease significantly, which explain this phenomenon.

\section{CONCLUSIONS}

Through the material and structure experiment analysis on the hydraulic steel gate which operated for many years and rusted seriously, the results are as follows:

(1) After years of corrosion, rust composition on the surface of the hydraulic steel gate structure is $\mathrm{Fe}_{2} \mathrm{O}_{3}$ and there are some cracks on the surface. The distribution of the corrosion product is as a block.

(2) After years of corrosion, the material chemical composition of the hydraulic steel gate structure does not change.

(3) After years of corrosion, the mechanics performance of the hydraulic steel gate structure material does not change.

(4) The main reason of the Hydraulic steel gate structure resistance attenuation is that the corrosion causes the declension of stress area, with the increase of corrosion, A will gradually decrease, $\mathrm{f}$ is changeless, therefore resistance $\mathrm{R}$ gradually decreases. Where $R$ is Structure of the force majeure, $A$ is the stress area, $f$ is the yield strength of material.

When resistance is less than the load effect of structures, the structure is in a failure state, its safe operation will be on a lot of potential safety problems.

\section{ACKNOWLEDGMENT}

The research work was supported by National Natural Science Foundation of China under Grant No. 51179011.

\section{REFERENCES}

[1] Zhang Yaohua, Wang Tiecheng, Yang Jianjiang, Reliability analysis for existing structures considering reduction of resistances with time. Journal of Shandong Agricultural University (Natural Science), 3, pp. 429-435, 2006.

[2] Gong Jinxin, Zhao Guofan, Reliability analysis for deteriorating structures. Journal of Building Structures, 5, pp. 43-51, 1998.

[3] Lin Yongjun, Qian Yongjiu, Analysis of the reliability index reference value of members considering change in resistance with time. Industrial Construction, 2, pp. 50-51, 2005.

[4] Zhou Jianfang, Li Dianqing, Li Zhaohui, et al., Time-variant resistance model and reliability analysis of steel gate structures. Engineering Mechanics, 4, pp. 104-109, 2003.

[5] Ren Yushan, Study on estimation of remaining life of members of existing hydraulic steel gates. Engineering Journal of Wuhan University, 38(6), pp. 62-65, 2005.

[6] Zhou Jianfang, Li Dianqing, Reliability Analysis for Hydraulic Steel Gate Structure. China Water Power Press, Beijing, 2008.

[7] Yuan Zexin, Yu Zongsen, Li Shiqi, et al., Study on the relationship between chemical compositions and mechanical properties of steels made by Wuhan Iron and steel corporation. Journal of Wuhan Yejin University of Science and Technology, 4, pp. 30-34, 1998.

[8] GB/T228-2002. Metallic Materials-Tensile Testing at Ambient Temperature. Standards Press of China, Beijing, 2002.

[9] GB/T700-1988. Carbon Structural Steels. Standards Press of China, Beijing, 1988. 